Accepted, revised and published in Electrophoresis,2011, 32 (11), pp. 1394-1401. DOI:10.1002/elps.201100005

\title{
DETERMINATION OF BETAINES IN VEGETABLE OILS BY CAPILLARY ELECTROPHORESIS TANDEM MASS SPECTROMETRY. APPLICATION TO THE DETECTION OF OLIVE OIL ADULTERATION WITH SEED OILS
}

LAURA SÁNCHEZ-HERNÁNDEZ, MARÍA CASTRO-PUYANA, MARÍA LUISA MARINA, ANTONIO L. CREGO *

Department of Analytical Chemistry, Faculty of Chemistry, University of Alcalá. Ctra. Madrid-Barcelona Km. 33.600, 28871 Alcalá de Henares (Madrid), Spain.

Running title: determination of betaines in vegetable oils by CE-MS/MS

*Corresponding author (phone + 34-91-8855076; fax $+34-91-8854971$; e-mail antonio.crego@uah.es)

Keywords: Betaines; Capillary Electrophoresis; Corn oil; Olive oil; Soybean oil; Sunflower oil; Tandem Mass Spectrometry 


\begin{abstract}
A capillary electrophoresis-tandem mass spectrometry methodology enabling the simultaneous determination of betaines (glycine betaine, trigonelline, proline betaine and total content of carnitines) in vegetable oils was developed. Betaines were derivatized with butanol previous to their baseline separation in 10 min using a $0.1 \mathrm{M}$ formic acid buffer at $\mathrm{pH}$ 2.0. Ion trap conditions were optimized in order to maximize selectivity and sensitivity. Analytical characteristics of the proposed method were established by evaluating its selectivity, linearity, precision (RSDs ranged from $4.8 \%$ to $10.7 \%$ for corrected peak areas), accuracy by means of recovery studies (from $80 \%$ to $99 \%$ ) and LODs and LOQs at $0.1 \mathrm{ppb}$ level. The method was applied to the determination of the selected betaines in seed oils and extra virgin olive oils. $\mathrm{MS}^{2}$ experiments provided the fingerprint fragmentation for all betaines studied in seed oils. In extra virgin olive oils, carnitines were not detected being possible to propose them as a feasible novel marker for the detection of adulterations of olive oils. Application of the developed method to the analysis of different mixtures of extra virgin olive oil with seed oil (between 2-10\%) enabled the detection and quantitation of the total content of carnitines. The results obtained show the high potential of the developed method for the authentication and quality control of olive oils.
\end{abstract}




\section{Introduction}

Olive oil shows outstanding characteristics due to its differentiated sensorial qualities and its high nutritional value [1]. Different studies have shown the relationship between the consumption of olive oil and its protective effect against cancer (especially colorectum and breast cancer) and cardiovascular disease [2-5]. Because of its high price, extra virgin olive oil is often illegally adulterated by fraudulent producers with cheaper oils such as sunflower, corn or soybean oils $[6,7]$. However, the definition of virgin oils established in the European regulations excludes the mixture with oils of other kinds [8]. For these reason, the fight against olive oil adulteration is a relevant aspect to determine the authenticity and quality of edible oils.

Despite that different spectrometric techniques in conjunction with multivariate parametric analysis have been applied to establish oil authenticity [9], most of the current works on edible oil adulteration employ chromatographic analysis [6]. Coupling these techniques with MS detection provides a powerful technique for the unequivocal determination of particular compounds in oils. Thus, different methodologies by GC-MS $[10,11]$ and HPLC-MS [1, 12-14] have been reported in the literature for the authentication of olive oils using as markers triacylglycerols or fatty acids (the main compounds of any edible oil). Although the unsaponifiable fraction, which makes up around 2-5\% of all oils, has been less studied, there are also different methods by GCMS and HPLC-MS described in the literature, that consider volatile compounds [15], aliphatic and triterpene alcohols [16], or tocopherols and sterols [13, 17] as markers for the detection of adulterations. However, most of these methodologies need sophisticated chemometric tools to interpret the data and differentiate the adulterated samples from pure olive oils. Recently, our research group proposed for the first time the use of nonprotein amino acids as novel markers for the detection of adulterations of olive oils with 
seed oils [18]. In fact, the development of a CE-MS ${ }^{2}$ methodology enabling the identification and determination of six non-protein amino acids in vegetable oils allowed to propose ornithine and alloisoleucine as markers for the detection of adulterations of olive oils.

Betaines could also be included among the variety of substances of different structure that makes up the unsaponifiable fraction of oils. They are highly polar zwitterionic molecules possessing a quaternary ammonium group with a permanent positive charge and a carboxylic group. These compounds are known to be one of the major osmoregulating compounds accumulated in many plants in response to environmental stress [19]. In mammals, betaines act as osmolytes in most tissues regulation [20-22] and as source of methyl groups for methylation of homocysteine to originate methionine. The glycine betaine, proline betaine and trigonelline concentration of a wide range of foods has been surveyed by HPLC-UV [23], LC-MS [24] and CE-UV [25]. However, only the presence of glycine betaine was detected in a concentration of $0.11 \mathrm{mg} / 100 \mathrm{~g}$ olive oil [24] whereas proline betaine and trigonelline were not detected $[23,25]$. On the other hand, trigonelline has been identified in sunflower seeds and soybean seeds by CE-UV [25], UV-vis spectrophotometry [26] and HPLC-UV [27], while in corn seeds, both trigonelline and glycine betaine have been identified by HPLCUV [23] and MS [28-30]. With respect to carnitine, it has been radioisotopic determined in olives, showing a concentration of $0.5 \mathrm{mg} / 100 \mathrm{~g}$ [31]. Based on the results obtained by our research group using $\mathrm{CE}$ with $\mathrm{UV}$ detection on the presence of trigonelline in soybean and sunflower oils, but not in olive oils, trigonelline was proposed as a marker for the detection of adulterations of olive oils with seed oils [25].

The purpose of the present study was to investigate the potential of betaines as novel markers of adulterations of olive oils with seeds oils through the development of a 
sensitive CE-MS methodology enabling the simultaneous determination of betaines in vegetable oils (seeds and olive oils).

\section{Materials and method}

\subsection{Chemicals and samples}

All reagents were of analytical grade. Methanol and chloroform (used for sample extraction) and isopropanol (used for sheath liquid preparation) were supplied from Scharlau Chemie (Barcelona, Spain). Sodium hydroxide and hydrochloric acid from Merck (Darmstadt, Germany) were used to rinse the capillary. Formic acid from Riedelde Häen (Seelze, Germany) was used to prepare CE running buffer whose $\mathrm{pH}$ was adjusted with $25 \%$ ammonium hydroxide solution from Merck. Hydrogen chloride/1butanol solution from Fluka (Buchs, Switzerland) was used for betaines derivatization. Distilled water was deionized by using a Milli-Q system (Millipore, Bedford, MA, USA).

Trigonelline, glycine betaine, carnitine, acetylcarnitine and palmitoylcarnitine were supplied from Sigma (St. Louis, MO, USA). Proline Betaine was from Hallochem Pharma (Chongqing, China). Arbequina, Picual, and Hojiblanca extra virgin olive oils, refined sunflower oils, refined corn oils and refined soybean oils were acquired in different supermarkets (Madrid, Spain) from different trademarks.

\subsection{Preparation of solutions}

The separation buffer was $0.1 \mathrm{M}$ formic acid adjusted with $25 \%(\mathrm{v} / \mathrm{v})$ ammonium hydroxide solution to reach $\mathrm{pH} 2.0$.

Stock standard solutions were prepared by dissolving $1 \mathrm{mg} / \mathrm{mL}$ of each betaine in acetonitrile/water (40:60, v/v) and diluting them to get a mixture of betaines at the desired 
concentration. These solutions were stored at room temperature before use and $500 \mu \mathrm{L}$ were evaporated at $80{ }^{\circ} \mathrm{C}$ and 15 mbar in epperdorf tubes before their derivatization.

Sample preparation was carried out considering our previous method [25]. Briefly, $40 \mathrm{~g}$ of vegetable oils were weighed and extracted with $160 \mathrm{~mL}$ of methanol:chloroform $(2: 1, \mathrm{v} / \mathrm{v})$ and left at $-20^{\circ} \mathrm{C}$ overnight. After centrifugation $\left(4000 \mathrm{~g}, 15 \mathrm{~min}, 4^{\circ} \mathrm{C}\right)$ the upper phase was collected in a new tube and the bottom phase was washed with $100 \mathrm{~mL}$ of methanol/chloroform/water $(2: 1: 0.8, \mathrm{v} / \mathrm{v} / \mathrm{v})$, obtaining a new upper phase which was combined with the previous one. Then, the mixed fractions were washed with $40 \mathrm{~mL}$ of chloroform and $100 \mathrm{~mL}$ of water and centrifuged $\left(4000 \mathrm{~g}, 15 \mathrm{~min}, 4^{\circ} \mathrm{C}\right)$. The aqueous phase was separated for its evaporation at $80{ }^{\circ} \mathrm{C}$ to dryness and finally it was derivatized with butanol before injection in the CE system.

\subsection{Derivatization procedure}

Butyl ester derivatization of betaines was carried out following a reported procedure which was slightly modified [32]. Thus, $0.5 \mathrm{ml}$ or $1 \mathrm{ml}$ of the butanol derivatizing agent ( $3 \mathrm{~N} \mathrm{HCl}$ in butanol) was added to the evaporated extract of standards or samples, respectively and shaken in a vortex. The reaction was carried out in an oven at $80{ }^{\circ} \mathrm{C}$ during $30 \mathrm{~min}$. The derivatization process was stopped keeping the solution in the freezer during $5 \mathrm{~min}$. Then, the excess of the derivatizing agent was evaporated in a concentrator at $80{ }^{\circ} \mathrm{C}$. Finally, the analytes were reconstituted in $500 \mu \mathrm{l}$ of acetonitrile/water (40:60, v/v).

\subsection{CE-MS conditions}

A $\mathrm{HP}^{3 \mathrm{D}} \mathrm{CE}$ instrument (Agilent Technologies, Palo Alto, CA, USA) coupled through an orthogonal electrospray interface (ESI, model G1607A from Agilent 
Technologies) to a 3D Ion Trap mass spectrometer (model 1100 from Agilent Technologies) was employed. MS control and data analysis were carried out using LC/MSD Trap Software 5.2. Separations were performed using uncoated fused-silica capillaries of $50 \mu \mathrm{m}$ id with a total length of $60 \mathrm{~cm}$, which were purchased from Composite Metal Services (Worcester, England). Before first use, the capillary was conditioned with $1 \mathrm{M} \mathrm{NaOH}$ for $20 \mathrm{~min}$, followed by water for $5 \mathrm{~min}, 0.1 \mathrm{M} \mathrm{HCl}$ for 5 min and finally the separation buffer for $30 \mathrm{~min}$, in all cases at a 1 bar pressure. Between injections, the capillary was rinsed with the buffer solution for 2 min. The capillary temperature was $25^{\circ} \mathrm{C}$, the injections were made at the anodic end by pressure $(50 \mathrm{mbar}$ for $50 \mathrm{~s}$ ), and the applied voltage was $25 \mathrm{kV}$.

Electrical contact at the electrospray needle tip was established via a sheath liquid which consisted of isopropanol:water (50:50, v:v) containing $0.1 \%$ formic acid and delivered at a flow rate of $3.3 \mu \mathrm{L} / \mathrm{min}$ by a syringe pump (model 100, Holliston, USA) with SGE syringe of $10 \mathrm{~mL}$ from Supelco (Bellefonte, PA, USA). The nebulizer pressure and flow, and the drying gas temperature were 2 psi $\mathrm{N}_{2}$ and $3 \mathrm{~L} / \mathrm{min} \mathrm{N}_{2}$ at $300{ }^{\circ} \mathrm{C}$, respectively. The mass spectrometer operated with the ESI source in the positive ion mode $(4.5 \mathrm{kV})$ and it scanned at $50-280 \mathrm{~m} / \mathrm{z}$ range. The trap parameters were programmed in smart mode using values of compound stability and trap drive level of 50 and $100 \%$, respectively. The ion charge control mode operated to accumulate 100000 ions for a maximum accumulation time of $300 \mathrm{~ms}$ with one scan. The fragmentation in the ion trap was performed for $10 \mathrm{~ms}$ with fragmentation amplitude of $1.00 \mathrm{~V}$ and isolation width of $4.0 \mathrm{~m} / \mathrm{z}$ to obtain $\mathrm{MS}^{2}$ spectra during the run in Multiple Reaction Monitoring (MRM) mode. Extracted ion electropherograms (EIEs) were obtained using the smoothed option of the software (Gauss at 1 point). 


\section{Results and discussion}

\subsection{Optimization of derivatization conditions for betaines}

The derivatization of compounds that contain mono- and dicarboxylic acid groups using butanol as derivatizing agent not only greatly improves ionization efficiencies and hence analytical sensitivity [33], but also improves the mass differentiation among the analytes increasing the selectivity. As a consequence, butanol was employed in this work as derivatizing agent for betaines in order to develop a CE-MS ${ }^{2}$ methodology enabling their sensitive determination in vegetable oils.

The efficiency of the derivatization reaction was optimized monitoring by UV detection the percentage of the derivatization achieved for trigonelline (betaine with a chromophore group). To obtain the maximum percentage, the temperature and the derivatization time were varied from 60 to $100{ }^{\circ} \mathrm{C}$ (butanol boiling point, $117.73{ }^{\circ} \mathrm{C}$ ) and from 10 to $30 \mathrm{~min}$, respectively. A percentage of $100 \%$ for the derivatization reaction was obtained when the temperature increased up to $80^{\circ} \mathrm{C}$. Figure 1 shows that when a percentage of derivatization of $62 \%$ was achieved (at $60{ }^{\circ} \mathrm{C}$ ), two peaks corresponding to derivatized and underivatized trigonelline appeared in the electropherogram (Figure 1a). However, at $80{ }^{\circ} \mathrm{C}$ (100\% derivatization reaction), only one peak, corresponding to derivatized trigonelline was observed (Figure 1b). On the other hand, the variation of the reaction time from 30 to $10 \mathrm{~min}$ decreased the percentage up to $55 \%$. As a consequence, $80{ }^{\circ} \mathrm{C}$ and 30 min were chosen as optimal conditions enabling to reach values of $100 \%$ derivatization for trigonelline.

\subsection{Identification of betaines}

First, the individual identification of the different derivatized betaines in MS and $\mathrm{MS}^{2}$ modes was carried out. Six different betaines (glycine betaine, trigonelline, proline 
betaine, carnitine, acetylcarnitine and palmitoylcarnitine) were chosen since they are present in a high number of foods as mentioned in the introduction. According to our previous work [25] and taking into account the cationic nature of betaines, the running buffer was $0.1 \mathrm{M}$ formic acid at $\mathrm{pH} 2.0$ which makes negligible the electroosmotic flow and the interaction of these analytes with the capillary wall. Mass spectra obtained using MS experiments enabled to identify all the derivatized betaines. However, the derivatization of acetylcarnitine and palmytoilcarnitine produced non-expected molecular ions at $m / z 218$ due to their degradation to carnitine. For this reason, the differentiation between carnitine and other acylcarnitines was not possible, and a total content of carnitines was determined.

The fragmentation of the molecular ions determined previously in the MS mode was carried out. Figure 2 depicts the $\mathrm{MS}^{2}$ spectra and the proposed structures of the derivatized betaines. Neutral losses of $\mathrm{m} / \mathrm{z} 56$ corresponding to the derivatizing agent $\left(\mathrm{CH}_{3} \mathrm{CH}_{2} \mathrm{CH}=\mathrm{CH}_{2}\right)$ took place for all betaines. In addition, in the case of carnitines neutral losses of $\mathrm{m} / \mathrm{z} 59$ of the quaternary ammonium group and $\mathrm{m} / \mathrm{z} 18$ of a water molecule were observed. It should be noted that the molecular ions for all the studied compounds have sizes $\geq 150 \mathrm{~m} / \mathrm{z}$, due to the formation of the butyl derivative of the betaines, where the MS background noise is usually lower [34].

\subsection{Simultaneous separation of betaines by CE-MS}

Using the CE-MS mode and a capillary with a total length of $85 \mathrm{~cm}$, the separation of the studied compounds was achieved in 18 min showing the following order of elution: glycine betaine, trigonelline, proline betaine and carnitines. The values of resolution between adjacent peaks were 4, 3 and 15, respectively. Then, the capillary length was reduced to $60 \mathrm{~cm}$, which is the minimum length needed for CE-MS hyphenation, in order 
to decrease the analysis time. Figure 3 a shows the base-peak electropherogram (BPE) obtained for the mixture of betaines using the short capillary. The analysis time was reduced up to 10 min with all peaks at least baseline resolved.

To carry out the simultaneous identification of betaines in one run, $\mathrm{MS}^{2}$ experiment in MRM mode was employed, which also allowed to improve the selectivity and sensitivity. Thus, to obtain good sensitivity ( $\mathrm{S} / \mathrm{N}$ ratio) with enough precision, the ion trap parameters were optimized to achieve at least 10-15 points per peak. Different parameters, such as the maximum accumulation time (ranging from 50 to $300 \mathrm{~ms}$ ), the number of scans averaged (from 1 to 3 ), and the fragmentation time (from 10 to $40 \mathrm{~ms}$ ) were investigated. The optimal conditions enabling to increase the $\mathrm{S} / \mathrm{N}$ ratio and precision were set at $300 \mathrm{~ms}$ for the maximum accumulation time, one scan, and $10 \mathrm{~ms}$ for the fragmentation time. Using these values, at least 12 points per peak with a precision about $10 \%$ were obtained.

Finally, a stacking sample preconcentration following our previous work [25] was carried out to increase the sensitivity for sample analysis. Thus, the reconstitution of the samples in acetonitrile/water $(40: 60, \mathrm{v} / \mathrm{v})$ after the derivatization reaction, and a hydrodynamic injection of $50 \mathrm{~s}$ were employed. Figure $3 \mathrm{~b}$ shows the $\mathrm{MS}^{2}$ electropherograms for glycine betaine, trigonelline, proline betaine, and total content of carnitines in MRM mode under the optimal conditions.

\subsection{Study of the analytical characteristics of the developed CE-MS ${ }^{2}$ method}

Selectivity, linearity, precision, accuracy, limit of detection (LOD), and limit of quantitation (LOQ) of the developed method were established in order to show its suitability for the determination of betaines in vegetables oils. 
A good selectivity was obtained since the analysis of betaines was possible monitoring one precursor-product ion transition by $\mathrm{MS}^{2}$ experiments for all compounds (except in the case of carnitine, where three transitions were obtained). In addition, a resolution higher than base-line separation was achieved (see Figure 3a).

Linearity was established by plotting the corrected peak areas (Ac, peak area to migration time ratio) from the EIEs as a function of the concentration for each betaine using the external standard calibration method. The correlation coefficient (r), the intercept, and the slope are grouped in Table 1. Satisfactory results were obtained in terms of linearity with a correlation coefficient $>0.99$ for the average calibration plot, and with all the confidence intervals at $95 \%$ for intercept, including the zero value.

Precision was evaluated considering the instrumental and method repeatability as well as the intermediate precision (see Table 1) for a sample of a seed oil (sunflower oil (RSO-1)). The values of relative standard deviations (RSDs in \%) for corrected peak areas were always lower than $8 \%$ for repeatability and lower than $11 \%$ for intermediate precision, except for proline betaine which was not detected in the samples.

To test the accuracy, a recovery study was carried out by spiking a representative extra virgin olive oil sample (HEVOO-1) with 5 and $50 \mathrm{ng}$ of each betaine and injecting the samples in triplicate. Values of recovery ranging from $80 \%$ to $99 \%$ with RSDs $\leq 5 \%$ were obtained as shown in Table 1.

Finally, LODs and LOQs for betaines were calculated as the minimum analyte concentration yielding a $\mathrm{S} / \mathrm{N}$ ratio equal to 6 and 10 times, respectively [35]. Using this definition for the LOD, the " $\alpha$-error" (deciding that the component is present when it is not) and " $\beta$-error" (deciding that the component is absent when it is present) are well 
balanced (only $5 \%$ ). According to this definition, Table 1 groups the values for LOD and LOQ obtained for the solutions previous to their derivatization.

\subsection{Quantitation of betaines in vegetable oils.}

The determination of the studied betaines in vegetable oils (three different samples of each kind of seed oils and nine different samples of three different varieties of extra virgin olive oil) was performed using the MRM which enabled to obtain an improvement in the sensitivity and selectivity of the method.

To carry out the quantification of the samples, the single-point standard addition calibration was employed. Using this methodology, it is only necessary the injection of two samples solutions for each vegetable oil sample, i.e. the sample solution and the spiked sample containing a known amount of betaines $(0.1 \mu \mathrm{g} / \mathrm{mL}$ of each one $)$. The content of each betaine determined in the different samples is presented in Table 2. Although the content of proline betaine was not detected in any of the analyzed samples, it is important to highlight that is the first time that glycine betaine and total content of carnitines have been determined in soybean, corn, and sunflower oils. As Table 2 shows, the highest content was obtained for glycine betaine in all seed oils. The values obtained for the content of trigonelline and carnitines were similar, except in sunflower oils where trigonelline was about 2 times higher than the content of total carnitines. Regarding extra virgin olive oils, the amount of glycine betaine and trigonelline was around 40 and 30 times lower than the amount obtained in seed oils, respectively. The results obtained for trigonelline, differ from those obtained previously where this compound was not detected in olive oils [25]. This is because with MS the sensitivity was 20 times better than with UV detection ( $\mathrm{LOD}=1 \mathrm{ng} / \mathrm{g}$ ) and it was possible to detect low quantities of trigonelline in olive oils. However, note that, although in all olive oils trigonelline peaks were 
detected, contents were smaller than LOQ in all cases except for two Arbequina extra virgin olive oils (see Table 2). Finally, the content of carnitines was not detected or not quantifiable in extra virgin olive oils being a feasible novel marker for the detection of adulterations of olive oils by this methodology.

To demonstrate the method suitability for detecting adulterations using carnitines as markers, different mixtures of olive oils with seed oil (soybean oil) were analyzed. Adding percentages of 2, 5 and $10 \%(\mathrm{w} / \mathrm{w})$ of soybean oil in olive oil not only increases the quantity of glycine betaine and trigonelline in the sample, but also enables to quantify a certain content of carnitines (see Table 2). These results can be observed in Figure 4 which shows the EIEs obtained by $\mathrm{CE}-\mathrm{MS}^{2}$ for glycine betaine, trigonelline and total content of carnitines in a soybean oil sample (RSYO-3), an extra virgin olive oil sample (HEVOO-1), and the oil mixture of HEVOO-1 with a 5\% (w/w) of RSYO-3. This figure also shows the $\mathrm{MS}^{2}$ spectra employed to carry out the unequivocal identification of each compounds in the oil mixtures. Taking into account the results obtained in this work, the detection of adulterations of olive oils with other vegetable oils can be performed using as marker the total content of carnitines. In addition, the presence of glycine betaine or trigonelline at concentrations higher than $0.7 \mathrm{ng} / \mathrm{g}$ or $0.1 \mathrm{ng} / \mathrm{g}$, respectively, would suppose their adulteration with other vegetable oils. Therefore, better results for oil mixtures were achieved by this methodology than those previously obtained by UV detection where percentages $\geq 20 \%(\mathrm{w} / \mathrm{w})$ of refined soybean oil in olive oil could be detected. These data confirm the high potential of the developed method to easily determine the authenticity and quality of olive oils. 


\section{Concluding remarks}

The sensitive and simultaneous determination of betaines previous derivatization with butanol was performed using a CE-ESI-MS ${ }^{2}$ method. Ion trap variables were optimized and $\mathrm{MS}^{2}$ experiments in MRM mode were carried out to improve the sensitivity and selectivity. Satisfactory separation among the betaines with short analysis times (10 min) was obtained. The analytical characteristics of the developed method were studied achieving good sensitivity and adequate precision and accuracy for all the analytes. The optimized method was applied to the analysis of different commercial vegetable oils (extra virgin olive oils, soybean oils, sunflower oils and corn oils). The results revealed the presence of glycine betaine, trigonelline and carnitines in seed oils while proline betaine was not detected in any sample. Moreover, the absence of carnitines in olive oils enabled to propose them as novel markers for detecting adulterations of extra virgin olive oils with seed oils. These results show that the proposed methodology is a promising alternative offering a sensitive and rapid fingerprint of olive oils for quality control purposes.

\section{Acknowledgement}

Authors thank the Spanish Ministry of Science and Innovation (project CTQ200909022) and the Comunidad Autónoma of Madrid (Spain) and european funding from FEDER programme (project S2009/AGR-1464, ANALISYC-II). They also thank the University of Alcalá and the Comunidad Autónoma of Madrid for project CCG10UAH/AGR-5950. Laura Sánchez-Hernández thanks the Comunidad Autónoma of Madrid for her research contract. 


\section{References}

[1] Fasciotti, M., Pereira Netto, A.D., Talanta 2010, 81, 1116-1125.

[2] Owen, R.W., Giacosa, A., Hull, W.E., Haubner, R., Spiegelhalder, B., Bartsch, H., European J. Cancer 2000, 36, 1235-1247.

[3] Hashim, Y.Z., Eng, M., Gill, C.I.R., McGlynn, H., Rowland, I.R., Nutrition Reviews 2005, 63, 374-386.

[4] Simosen, M.R., Fernández-Crehuet Navajas, J., Martin-Moreno, J.M., Strain, J.J., Hutlenen, J.K., Martin, B.C., Thamn, M., Kardinaal, A.F.M., van`t Veer, P., Kok, F.J., Kohlmeier, L., Am J Clin Nutr 1998, 68, 134-41.

[5] Dibella, G., Maisana, R., LaPera, L., Lo Turco, V., Salvo, F., Dugo, G., J. Agric. Food Chem. 2007, 55, 6568-6574.

[6] Aparicio, R., Aparicio-Ruíz, R., J. Chromatogr A 2000, 881, 93-104.

[7] Frankel, E.N., J. Agric. Food Chem. 2010, 58, 5991-6006.

[8] European Communities. Regulation 865/2004. Off. J. Eur. Communities: Legis. 2004, 206, 37-50.

[9] Arvanitoyannis, I.S., Vlachos, A., Crit. Rev. Food Sci. Nutr. 2007, 47, 441-498.

[10] Capote, F.P., Jiménez, J.R., de Castro, M.D.L., Anal. Bioanal. Chem. 2007, 388, 1859-1865.

[11] Gamazo-Vázquez, J., García-Falcon, M.S., Simal-Gandara, J., Food Control 2003, $14,463-467$.

[12] Lisa, M., Holcapek, M., Bohac, M., J. Agric. Food Chem. 2009, 57, 6888-6898.

[13] Parcerisa, J. Casals, I., Boatella, J. Codany, R., Rafecas, M., J. Chromatrogr A 2000, 881, 149-158.

[14] Jakab, A, Hérberger, K., Forgács, E., J. Chromatogr. A 2002, 976, 255-263.

[15] Mildner-Szkudlarz, S., Jelen, H.H., J. Food Qual. 2010, 33, 21-41.

[16] Lerma-Garcia, M.J., Ramis-Ramos, G., Herrero-Martinez, J.M., GimenoAdelantaido, J.V., Simo-Alfonso, E.F., J. Chromatogr. A 2009, 1216, 230-236.

[17] A.S. Carretero, A. Carrasco-Pancorbo, S. Cortacero, A. Gori, L. Cerretani, A. Fernández-Gutiérrez, Eur. J. Lipid Sci. Technol. 2008, 110, 1142-1149.

[18] Sánchez-Hernández, L., Marina, M.L., Crego, A.L., J. Chromatogr. A, in press. 
[19] Zhang, J., Nishimura, N., Okubo, A., Yamazaki, S., Phytochemical Anal. 2002, 13, 189-194.

[20] Schlies, F., Häussinger, D., Biol Chem 2002, 383, 577-583.

[21] Lang, F., J. Am. Coll. Nutr. 2007, 26, 613S-623S.

[22] Lever, M., Slow, S., Clinical Biochem. 2010, 43, 732-744.

[23] de Zwart, F.J., Slow, S., Payne, R.J., Lever, M., George, P.M., Gerrard, J.A., Chambers, S.T., Food chemistry 2003, 83, 197-204.

[24] Zeisel, S.H., Mar, M-H., Howe, J.C., Holden, J.M., J. Nutr. 2003, 1302-1307.

[25] Sánchez-Hernández, L., Puchalska, P., García-Ruiz, C., Crego, A.L., Marina, M.L., J. Agric. Food Chem. 2010, 58, 7489-7496.

[26] Cho, Y., Turnipseed, E.B., Lightfoot, D.A., Wood, A.J., Biologia Plantarum 2008, $52,370-372$.

[27] Martínez-Villaluenga, C., Kuo, Y.H., Lambein, F., Frías, J., Vidal-Valverde, C., Eur. Food Res Technol 2006, 224, 177-186.

[28] Rhodes, D., Rich, P.J., Brunk, D.G., Ju, G.C., Rhodes, J.C., Pauly, M.H., Hansen, L.A., Plant Physiol. 1989, 91, 1112-1121.

[29] Rhodes, D., Rich, P.J., Myers, A.C., Reuter, C.C., Jamieson, G.C., Plant. Physiol. 1987, 84, 781-788.

[30] Peel, G.J., Mickelbart, M.V., Rhodes, D., Phytochemistry 2010, 71, 404-414.

[31] Demarquoy, J., George, B., Rigault, C., Royer, M-C., Clairet, A., Soty, M., Lekounoungou, S., Le Borgne, F., Food Chemistry 2004, 86, 137-142.

[32] Chace, D.H., Lim, T., Hansen, C.R., De Jesus, V.R., Hannon, W.H., Clin. Chim. Acta 2009, 407, 6-9.

[33] Donald H. Chace, Chem. Rev. 2001, 101, 445-477.

[34]Castro-Puyana, M., Garcia-Ruiz, C., Crego, A.L., Marina, M.L., Electrophoresis 2009, 30, 337-348.

[35] Massart, D.L., Vandeginste, B.G.M., Deming, S.N., Michotte, Y., Kaufman, L., in: B.G.M. Vandeginste and L. Kaufman (Eds.), Chemometrics: a Textbook, Data Handling in Science and Technology, 2, Amsterdam, 1988, pp. 107. 


\section{Figure Captions}

Figure 1. Electropherograms showing the effect of derivatization temperature for trigonelline at a) $60{ }^{\circ} \mathrm{C}$ and b) $80{ }^{\circ} \mathrm{C}$. CE conditions: BGE, $0.1 \mathrm{M}$ formic buffer (pH 2.0); uncoated fused-silica capillary, $50 \mu \mathrm{m}$ ID $\times 68.5 \mathrm{~cm}$; injection by pressure at $50 \mathrm{mbar} \times 15$ s; applied voltage, $25 \mathrm{kV}$; temperature, $25^{\circ} \mathrm{C}$; detection at $195 \mathrm{~nm}$. Standard of $50 \mu \mathrm{g} / \mathrm{mL}$ in water.

Figure 2. $\mathrm{MS}^{2}$ spectra and structure of precursor ions for each betaine are shown. CE conditions: BGE, 0.1 M formic buffer ( $\mathrm{pH} 2.0$ ); uncoated fused-silica capillary, $50 \mu \mathrm{m}$ ID $\times 85 \mathrm{~cm}$; injection by pressure at $50 \mathrm{mbar} \times 15 \mathrm{~s}$; applied voltage, $25 \mathrm{kV}$; temperature, 25 ${ }^{\circ} \mathrm{C}$. ESI conditions: positive ion mode; spray voltage, $4.5 \mathrm{kV}$; sheath liquid, isopropanol/water $(50 / 50 \mathrm{v} / \mathrm{v})$ with $0.1 \%$ formic acid at $3.3 \mu \mathrm{L} / \mathrm{min}$; drying gas flow, 3 $\mathrm{L} / \mathrm{min}$; drying temperature, $300{ }^{\circ} \mathrm{C}$; nebulizer pressure, 2 psi. Ion trap conditions: maximum accumulation time, $300 \mathrm{~ms}$; averages, 3; scan, 50-350 m/z; $\mathrm{MS}^{2}$ transitions with width, $4 \mathrm{~m} / \mathrm{z}$; fragmentation amplitude, $1.00 \mathrm{~V}$; fragmentation time, $40 \mathrm{~ms}$.

Figure 3 a) CE-MS base peak electropherogram (BPE) for standard betaines mixture of 5 $\mu \mathrm{g} / \mathrm{mL}$ each one (injection by pressure at $50 \mathrm{mbar} \times 15 \mathrm{~s}$ ) and b) simultaneous CE-MS ${ }^{2}$ EIE for a standard betaines mixture of $5 \mu \mathrm{g} / \mathrm{mL}$ each one (injection by pressure at 50 mbar $\times 50 \mathrm{~s}$ ). CE Conditions: uncoated fused-silica capillary, $50 \mu \mathrm{m}$ ID×60 cm; Other CE conditions and ESI conditions as in Fig. 2. Ion trap conditions: maximum accumulation time, $300 \mathrm{~ms}$; averages, 1; scan, 50-280 m/z. $\mathrm{MS}^{2}$ transitions in MRM mode with width, $4 \mathrm{~m} / \mathrm{z}$; fragmentation amplitude, 1.00 and fragmentation time, $10 \mathrm{~ms}$. Peak 1. Glycine betaine, 2. Trigonelline, 3. Proline betaine, 4. Carnitine and Acetylcarnitine. Standards dissolved in acetonitrile/water $(40: 60, v / v)$.

Figure 4. CE-MS ${ }^{2}$ EIE for glycine betaine, trigonelline and total content of carnitines in a) soybean oil sample (RSYO-3), b) extra virgin olive oil sample (HEVOO-1), c) oil mixture 
of HEVOO-1 with a 5\% (w/w) of RSYO-3, and d) $\mathrm{MS}^{2}$ spectra for the peaks obtained in c) of glycine betaine, trigonelline or carnitines in the oil mixtures (HEVOO-1 with a 5\% (w/w) of RSYO-3). All other experimental conditions were as in Fig. 3. 
Table 1. Analytical characteristics of the method developed for the determination of betaines by CE-MS ${ }^{2}$ a)

\begin{tabular}{|c|c|c|c|c|c|c|c|c|c|c|c|c|c|}
\hline \multirow{3}{*}{ Compound } & \multicolumn{3}{|c|}{ Linearity $^{\mathrm{b})}$} & \multicolumn{6}{|c|}{ Precision $(\mathrm{Ac} \text { and } \mathrm{RT}, \mathrm{RSD}(\%))^{\mathrm{c})}$} & \multicolumn{2}{|c|}{ Recovery $^{\mathrm{g})}$} & \multirow{3}{*}{$\begin{array}{l}\text { LOD } \\
\text { (ng/g) }\end{array}$} & \multirow{3}{*}{$\begin{array}{l}\text { LOQ } \\
(\mathrm{ng} / \mathrm{g})\end{array}$} \\
\hline & \multirow[t]{2}{*}{$\mathrm{r}$} & \multirow[t]{2}{*}{ Intercept } & \multirow[t]{2}{*}{ Slope } & \multicolumn{2}{|c|}{$\begin{array}{l}\text { Instrumental } \\
\text { Repeatabilityd) }\end{array}$} & \multicolumn{2}{|c|}{$\begin{array}{c}\text { Method } \\
\text { Repeatability }\end{array}$} & \multicolumn{2}{|c|}{$\begin{array}{l}\text { Intermediate } \\
\text { Precision }\end{array}$} & \multirow[t]{2}{*}{$\begin{array}{l}\text { Low } \\
\text { level }\end{array}$} & \multirow[t]{2}{*}{$\begin{array}{l}\text { High } \\
\text { level }\end{array}$} & & \\
\hline & & & & Ac & $\mathrm{RT}$ & Ac & $\mathrm{RT}$ & Ac & RT & & & & \\
\hline Glycine betaine & 0.996 & $7.5( \pm 7.6) \times 10^{3}$ & $109.9( \pm 8.3)$ & 4.8 & 5.5 & 7.7 & 6.8 & 10.7 & 11.2 & $99 \pm 2$ & $94 \pm 1$ & 0.075 & 0.125 \\
\hline Trigonelline & 0.994 & $12.8( \pm 15.8) \times 10^{3}$ & $148.3( \pm 30.3)$ & 5.8 & 5.9 & 7.4 & 8.9 & 9.5 & 10.2 & $92 \pm 5$ & $88 \pm 2$ & 0.050 & 0.083 \\
\hline Proline betaine & 0.997 & $1.9( \pm 9.4) \times 10^{3}$ & $75.6( \pm 10.6)$ & & & & & & - & $80 \pm 5$ & $88 \pm 2$ & 0.075 & 0.125 \\
\hline Carnitines & 0.994 & $8.2( \pm 12.0) \times 10^{3}$ & $241.9( \pm 22.8)$ & 5.4 & 7.7 & 7.9 & 8.9 & 9.1 & 12.5 & $96 \pm 1$ & $99 \pm 1$ & 0.050 & 0.083 \\
\hline
\end{tabular}

a) Experimental conditions as in Fig. 3 .

b) Six standard solutions at different concentration levels (LOQ-100LOQ) injected in triplicate during three days. The calibration plot was represented using the average of the triplicate injections for each day. Values in parentheses are confidence intervals at $95 \%$ : $\pm \mathrm{t} \times \mathrm{S}_{\mathrm{intercept}}$, $\pm \mathrm{t} \times \mathrm{S}_{\text {slope }}$.

c) Ac means corrected peak area (peak area divided by migration time) and RT means retention time.

d) Obtained from six consecutive injections of RSO-1 in the same day $(n=6)$.

e) Obtained from three individual RSO-1 samples injected by triplicate in the same day $(n=3)$.

f) Assessed from three individual RSO-1 samples injected in triplicate in three consecutive days ( $\mathrm{n}=9$ ).

${ }^{\text {g) }}$ Recovery for HEVOO-1 samples spiked at low level (5 ng of each compound) and at high level (50 ng of each compound). Average \pm standard deviation $(n=3)$. 
Table 2. Quantitation of betaines (using the single point standard addition) in vegetable oils from different botanical origin. ND: not detected (<LOD).

\begin{tabular}{|c|c|c|c|c|c|}
\hline \multirow[b]{2}{*}{ Origin } & \multirow[b]{2}{*}{ Sample Name } & \multicolumn{4}{|c|}{ Quantitation $(n g / g)$} \\
\hline & & $\begin{array}{l}\text { Glycine } \\
\text { betaine }\end{array}$ & Trigonelline & $\begin{array}{l}\text { Proline } \\
\text { betaine }\end{array}$ & $\begin{array}{l}\text { Carnitine and } \\
\text { Acylcarnitines }\end{array}$ \\
\hline \multirow{3}{*}{ Sunflower oil } & $R S O-1$ & $9 \pm 1$ & $5.5 \pm 0.1$ & ND & $2.1 \pm 0.5$ \\
\hline & $R S O-2$ & $12 \pm 1$ & $6.7 \pm 0.1$ & ND & $4.4 \pm 0.3$ \\
\hline & $R S O-3$ & $11 \pm 1$ & $7.7 \pm 0.6$ & ND & $2.2 \pm 0.3$ \\
\hline \multirow{3}{*}{ Corn oil } & $R C O-1$ & $4 \pm 1$ & $0.3 \pm 0.1$ & ND & $0.3 \pm 0.1$ \\
\hline & $R C O-2$ & $8 \pm 1$ & $1.1 \pm 0.7$ & ND & $0.8 \pm 0.2$ \\
\hline & $R C O-3$ & $5 \pm 2$ & $0.5 \pm 0.1$ & ND & $1.0 \pm 0.3$ \\
\hline \multirow{3}{*}{ Soybean oil } & $R S Y O-1$ & $4 \pm 1$ & $0.7 \pm 0.1$ & ND & $1.1 \pm 0.2$ \\
\hline & $R S Y O-2$ & $9.7 \pm 0.8$ & $1.2 \pm 0.3$ & ND & $1.0 \pm 0.3$ \\
\hline & RSYO-3 & $5.4 \pm 0.4$ & $0.6 \pm 0.2$ & ND & $0.8 \pm 0.1$ \\
\hline \multirow{3}{*}{$\begin{array}{c}\text { Hojiblanca } \\
\text { extra virgin } \\
\text { olive oil }\end{array}$} & HEVOO-1 & $0.16 \pm 0.01$ & $<\mathrm{LOQ}$ & ND & $<\mathrm{LOQ}$ \\
\hline & HEVOO-2 & $0.12 \pm 0.01$ & $<$ LOQ & ND & ND \\
\hline & HEVOO-3 & $<$ LOQ & $<\mathrm{LOQ}$ & ND & ND \\
\hline \multirow{3}{*}{$\begin{array}{c}\text { Arbequina } \\
\text { extra virgin } \\
\text { olive oil }\end{array}$} & $A E V O O-1$ & $0.13 \pm 0.02$ & $0.085 \pm 0.007$ & ND & ND \\
\hline & $A E V O O-2$ & $0.24 \pm 0.01$ & $<$ LOQ & ND & $<$ LOQ \\
\hline & AEVOO-3 & $0.19 \pm 0.01$ & $0.089 \pm 0.001$ & ND & ND \\
\hline \multirow{3}{*}{$\begin{array}{c}\text { Picual extra } \\
\text { virgin olive oil }\end{array}$} & PEVOO-1 & $<$ LOQ & $<\mathrm{LOQ}$ & ND & $<$ LOQ \\
\hline & PEVOO-2 & $0.12 \pm 0.02$ & $<\mathrm{LOQ}$ & ND & ND \\
\hline & PEVOO-3 & $0.14 \pm 0.01$ & $<\mathrm{LOQ}$ & ND & ND \\
\hline \multirow{3}{*}{$\begin{array}{c}\text { Mixtures of } \\
\text { HEVOO-1 } \\
\text { with RSYO-3 }\end{array}$} & $10 \%$ & $0.68 \pm 0.01$ & $0.12 \pm 0.04$ & ND & $0.14 \pm 0.01$ \\
\hline & $5 \%$ & $0.45 \pm 0.03$ & $0.09 \pm 0.02$ & ND & $0.096 \pm 0.006$ \\
\hline & $2 \%$ & $0.36 \pm 0.02$ & $<$ LOQ & ND & $<$ LOQ \\
\hline
\end{tabular}


Figure 1.

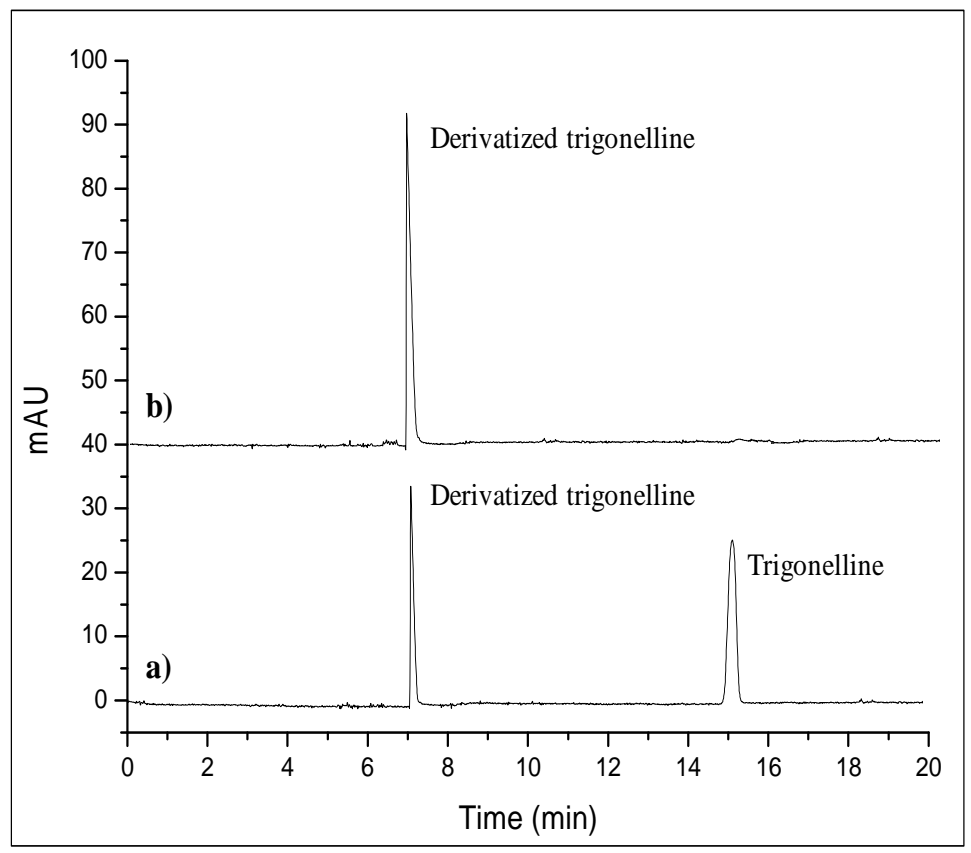


Figure 2.
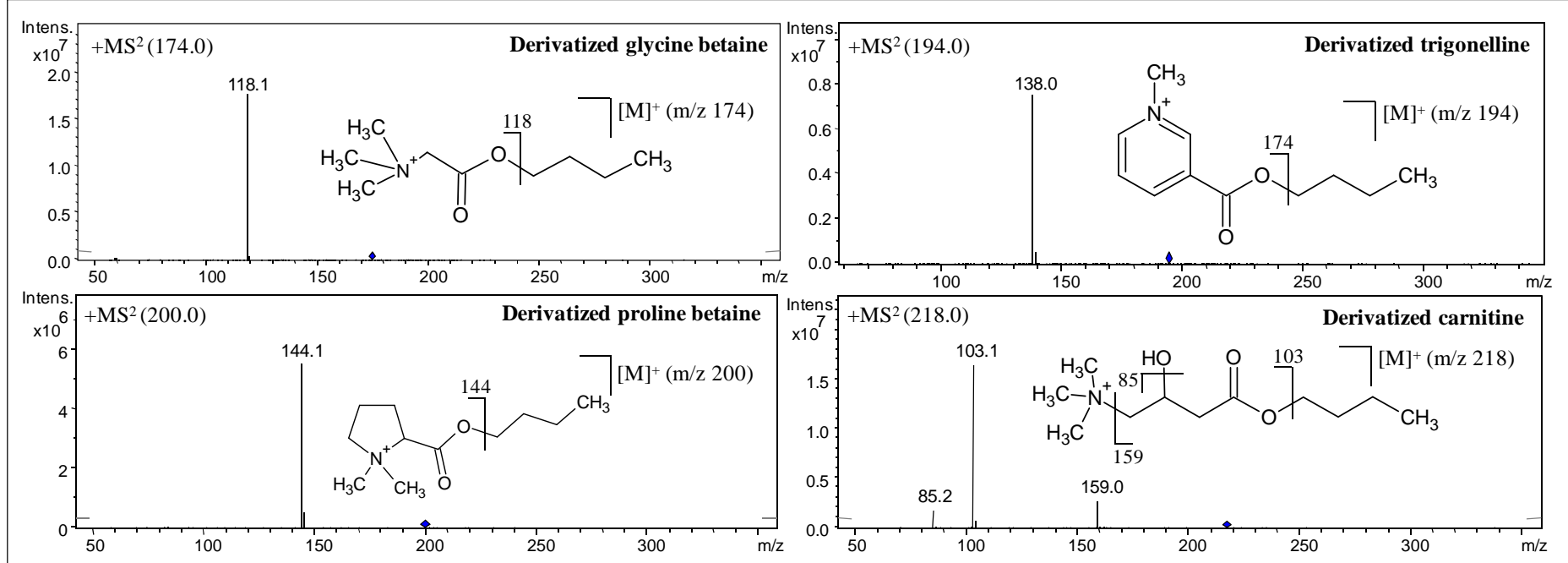
Figure 3.
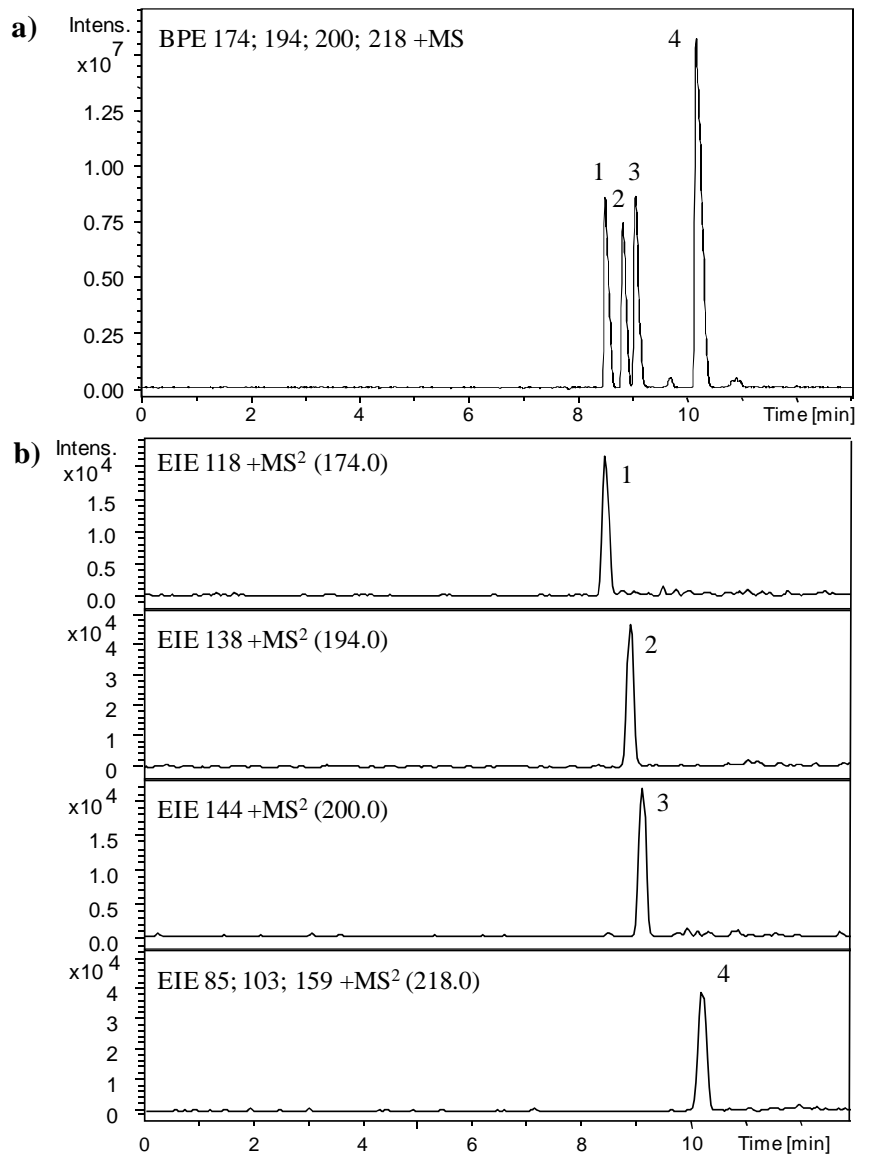
Figure 4
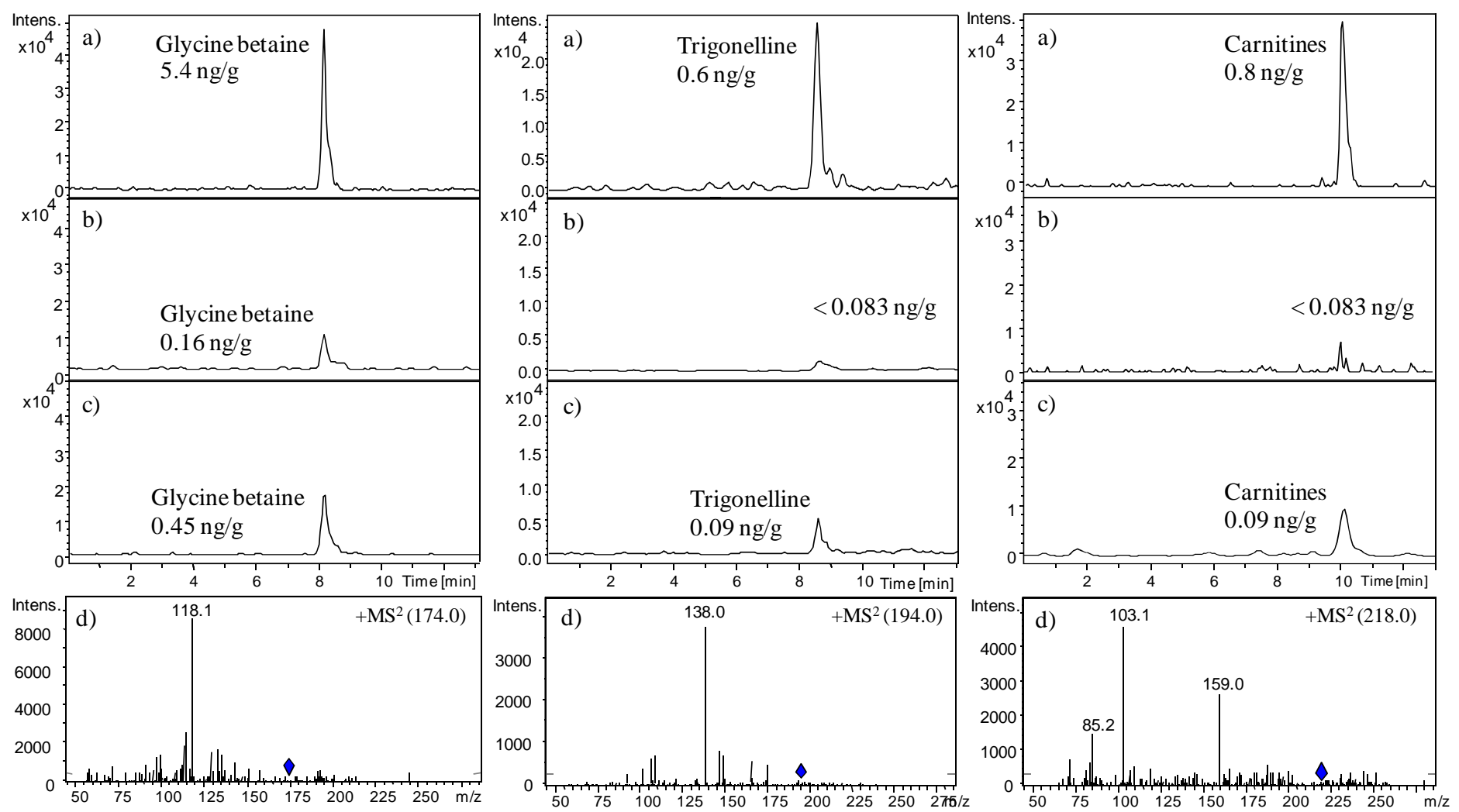